\title{
molecules
}

ISSN 1420-3049

www.mdpi.com/journal/molecules

Article

\section{Synthesis and Anti-Trypanosoma cruzi Activity of Diaryldiazepines}

\author{
Júlio César L. Menezes ", Luana Beatriz A. Vaz ${ }^{2}$, Paula Melo de Abreu Vieira ${ }^{2}$, \\ Kátia da Silva Fonseca ${ }^{2}$, Cláudia Martins Carneiro ${ }^{2}$ and Jason G. Taylor ${ }^{1, *}$
}

1 Departamento de Química, ICEB, Universidade Federal de Ouro Preto, Campus Morro do Cruzeiro, CEP, Ouro Preto, MG 35400-000, Brazil; E-Mail: jc_menezes2@hotmail.com

2 Laboratório de Imunopatologia, Núcleo de Pesquisas em Ciências Biológicas, ICEB II, Morro do Cruzeiro, Universidade Federal de Ouro Preto, Ouro Preto 35400-000, Brazil;

E-Mails: luanavazz@yahoo.com.br (L.B.A.V.); paulinhamav@gmail.com (P.M.A.V.); katia.fonseca@gmail.com (K.S.F.); claudiamartinscarneiro@gmail.com (C.M.C.)

* Author to whom correspondence should be addressed; E-Mail: jason@iceb.ufop.br; Tel.: +55-313-559-1707.

Academic Editor: Derek J. McPhee

Received: 14 October 2014 / Accepted: 18 November 2014 / Published: 23 December 2014

\begin{abstract}
Chagas disease is a so-called "neglected disease" and endemic to Latin America. Nifurtimox and benznidazole are drugs that have considerable efficacy in the treatment of the acute phase of the disease but cause many significant side effects. Furthermore, in the Chronic Phase its efficiency is reduced and their therapeutic effectiveness is dependent on the type of $T$. cruzi strain. For this reason, the present work aims to drive basic research towards the discovery of new chemical entities to treat Chagas disease. Differently substituted 5,7-diaryl-2,3-dihydro-1,4-diazepines were synthesized by cyclocondensation of substituted flavones with ethylenediamine and tested as anti-Trypanosoma cruzi candidates. Epimastigotes of the $\mathrm{Y}$ strain from $T$. cruzi were used in this study and the number of parasites was determined in a Neubauer chamber. The most potent diaryldiazepine that reduced epimastigote proliferation exhibited an $\mathrm{IC}_{50}$ value of $0.25 \mu \mathrm{M}$, which is significantly more active than benznidazole.
\end{abstract}

Keywords: diaryldiazepines; Trypanosoma cruzi; Chagas disease; epimastigote 


\section{Introduction}

Seven-membered heterocycles with two nitrogen's in a 1,4-relationship are classified as diazepines. Diazepines are well known for their unique pharmacological activity and in particular, the 1,4-benzodiazepines are especially recognized for their effects on the central nervous system [1]. In the last 10 years, a variety of 1,4-diazepines have been reported for various biological activities, such as anti-schistosomal activity [2], apoptosis inhibitors [3], Nox4/Nox1 inhibitors [4] and anticonvulsant activity, [5] amongst others. In the specific case of diaryldiazepines, antiproliferative and cytotoxic activities were demonstrated in vitro against several human leukemic cells, such as Jurkat, HL60, MOLT3, NCEB-1 and K562 [6]. However, in general, diaryldiazepines have been underexplored for other types of diseases and this is surprising given the possibility to modulate its activity by incorporating different substituents on the phenyl rings (Figure 1).

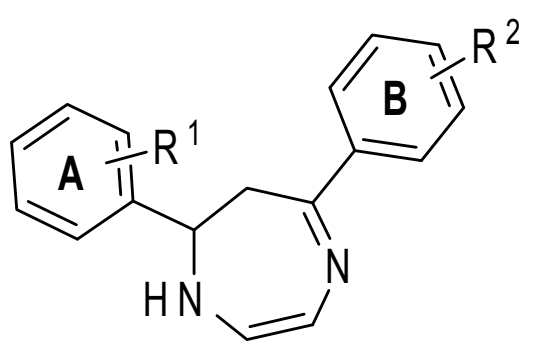

Figure 1. Chemical structure of diaryldiazepines.

The present work is part of our ongoing medicinal chemistry project funded by the Brazilian government, which aims to drive basic research towards solving neglected tropical diseases (NTD). American trypanosomiasis, also known as Chagas disease [7], is included in the NTD list and is endemic to 21 Latin American countries [8,9]. The protozoan hemoflagellate Trypanosoma cruzi is the etiologic agent responsible for Chagas disease. The disease is a so-called "neglected disease" because health markets in affected countries are insufficient to attract pharmaceutical industry to invest in research and development. Thus, the biggest obstacle to treating the disease has been the discovery and development of new chemical entities able to meet this deficit in innovation. The two drugs currently available for treating Chagas disease are nifurtimox and benznidazole, which are chemically related nitro-heterocycles (Figure 2).

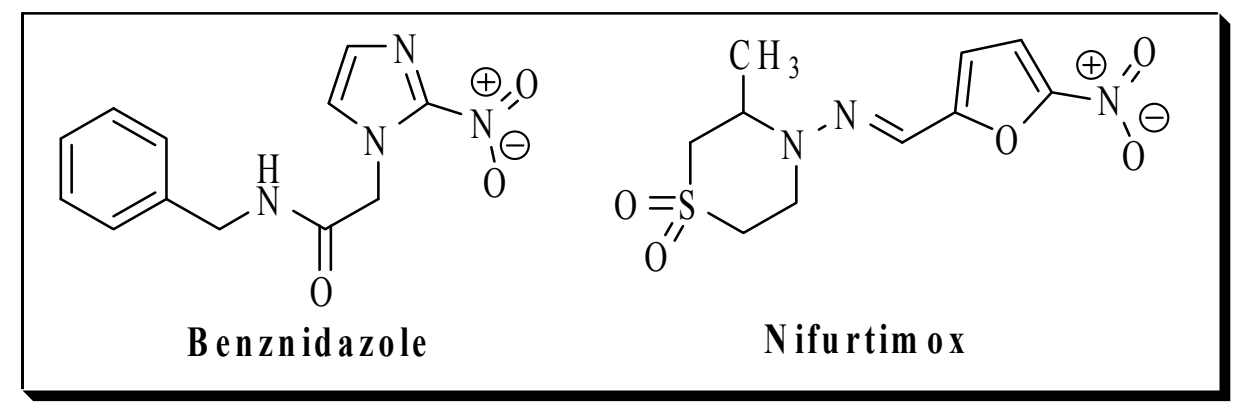

Figure 2. Chemical structures of benznidazole and nifurtimox. 
Unfortunately, they both result in many significant side effects such as oedema, fever, rash, agranulocytosis and neurotoxicity. In comparison with benznidazole, not only are the side effects of nifurtimox more severe, it has lower efficacy and so the commercialization of nifurtimox was suspended in Brazil, Argentina, Chile and Uruguay in the 1980s [10]. Additionally, the therapeutic effectiveness of nifurtimox and benznidazole is dependent on the type of T. cruzi strain, since certain strains are more resistant than others [11]. Thus, due to the limitations of these treatments, they are not ideal drugs and this drives the search for new more efficient compounds.

A number of studies focused on the synthesis and in vitro activity of biologically active compounds against $T$. cruzi have been reported in the literature. Recent examples include thiazolidinones [12], 1,2,4-triazole-3-thiones [13], aryloxyindole-4,9-diones [14], 4-arylthiazolylhydrazones [15], oxadiazoles [16] and Morita-Baylis-Hillman adducts [17]. Promising results are indicated by potencies that are either equal to or better than benznidazole with varying degrees of mammalian cell toxicity observed depending on the compound class (Figure 3). The aryloxyindoles stand out for their high potency but in general, $\mathrm{IC}_{50}$ values in the range of 4-30 $\mu \mathrm{M}$ have been considered promising candidate leads.

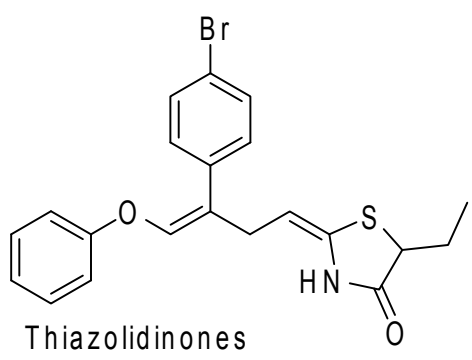

$\mathrm{IC}_{50}[\mu \mathrm{m}]: 3.9$ (epim astigotes)

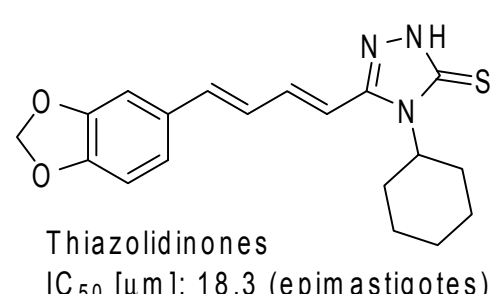

$\mathrm{IC}_{50}[\mu \mathrm{m}]: 18.3$ (epimastigotes)<smiles>CCOC(=O)c1cc2c(n1CC)C(=O)C(Oc1ccc(C)cc1)=CC2=O</smiles>

Aryloxyindole-4,9-diones

$I_{50}[\mu \mathrm{m}]: 0.02$ (epimastigotes)
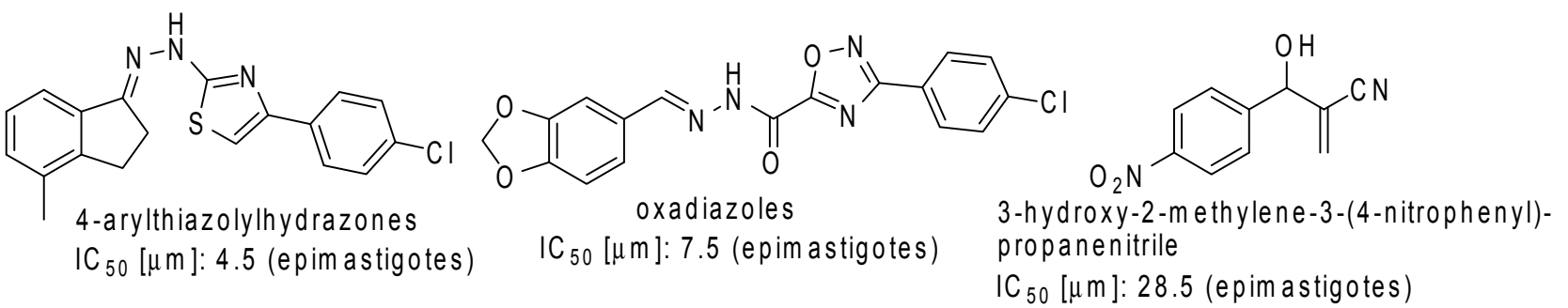

Figure 3. Compounds with anti-T. cruzi activity.

In order to meet this deficit in new drug candidates for Chagas disease, we have prepared and tested against $T$. cruzi six diaryldiazepines analogous.

\section{Results and Discussion}

The synthesis of the target diazepine was commenced with the esterification of 2-hydroxyacetaphenone with substituted benzoyl chlorides as illustrated in Scheme 1.

A Baker-Venkataraman rearrangement induced by $\mathrm{KOH}$ affords 1,3-diketones $\mathbf{2 a}-\mathbf{f}$, which undergo condensation under refluxing acetic acid to provide flavones 3a-f. All ester, 1,3-diketone and flavone intermediates were confirmed by comparison of their melting point and NMR spectral data with literature values. All data for these intermediates were in complete accordance with literature values. Flavones 3a-f reacted with ethylenediamine to afford the required diaryldiazepines in reasonable 
yields and high purity. Their spectroscopic data were in accordance with those previously reported [6]. Only diazepine 4d is novel and was therefore fully characterized by FT-IR, NMR and Mass Spectrometry. To evaluate the possible influence of substituent effects, we prepared diaryldiazepines which either contained an electron donating or withdrawing group.
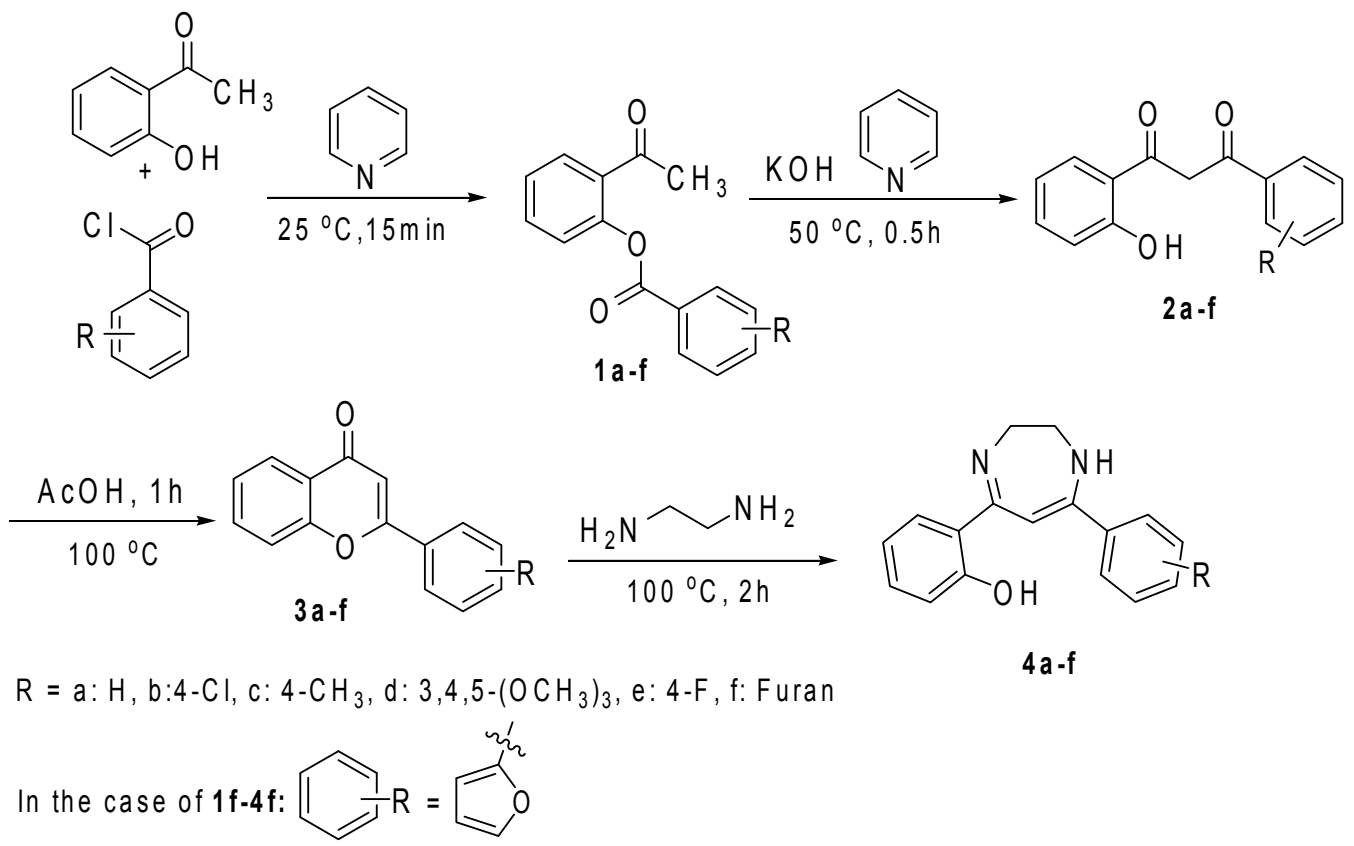

Scheme 1. Synthesis of Diazepines 4a-f.

Once the final products were purified and fully characterized, we carried out in vitro bioassays using epimastigotes forms (i.e., the form present in the midgut vector) of Y-strain T. cruzi, which provided the inhibitory concentration as summarized in Table 1.

Table 1. Trypanocidal activity of diazepines $\mathbf{4 a - f}$ against the epimastigotes forms of Y-strain T. cruzi.

\begin{tabular}{cc}
\hline Compound & $\begin{array}{c}\text { Trypanocidal Activity } \\
\mathbf{I C}_{\mathbf{5 0}}(\boldsymbol{\mu} \mathbf{M})\end{array}$ \\
\hline Benznidazole & 10.8 \\
$\mathbf{4 a}$ & 10.6 \\
$\mathbf{4 b}$ & 0.25 \\
$\mathbf{4 c}$ & 34.2 \\
$\mathbf{4 d}$ & 26.8 \\
$\mathbf{4 e}$ & 4.2 \\
$\mathbf{4 f}$ & Not Active \\
\hline
\end{tabular}

$\mathrm{IC}_{50}$ : Represents the concentration required to give $50 \%$ inhibition.

In Brazil, benznidazole is the only therapy used in etiological treatment with direct action against intracellular trypomastigotes of the Trypanosoma cruzi parasite. Precisely for this reason, it is the only drug used as a standard control in our experiments. However, due to numerous side effects caused by this drug and resistance build up by different strains of the parasite, several compounds have been 
studied in the search for new treatments [12-17]. Herein, 6 Diazepines compounds were assayed directly against the epimastigotes forms of $T$. cruzi.

Among the diazepines tested, $\mathbf{4 a}, \mathbf{4 b}$ and $\mathbf{4 e}$ were found to be the most potent trypanosomicides against epimastigotes and in particular, diazepine $\mathbf{4 b}$ was 40 times more potent than our positive control, benznidazole. The furan bearing diazepine was essentially inactive and it was therefore not possible to calculate an $\mathrm{IC}_{50}$ for $\mathbf{4 f}$ with any statistical confidence due its low activity. No cytotoxicity was observed for this same compound against human leukemic cancer cell lines [6].

Diazepine $4 \mathbf{b}$ showed $78 \%$ inhibition at the lowest concentration tested and this result highlights the remarkable effect that the chloro group has on the activity of the 5,7-diaryldiazepine. In contrast, the presence of electron donating methoxy groups are slightly unfavourable towards anti-trypanocidal activity. Our results contrast to those of Ramajayam and collaborators [6] in which cytotoxicity activity of 5,7-diaryldiazepines was highest for the methyl group bearing diaryldiazepine. Similarly, electron-donating groups i.e., the methoxy substituents, lowered cytotoxicity. In the present study, these analogues were also less active against T.cruzi.

Ramajayam and collaborators found that antiproliferative activity for halogen group bearing diaryldiazepines was moderate, but from the data obtained in the present study, this analogue was significantly more active against $T$. cruzi with compound $4 \mathbf{e}$ being the next most active against epimastigotes of $T$. cruzi. In contrast, the $\mathrm{IC}_{50}$ for cytotoxicity of $\mathbf{4 b}$ against human leukemic cancer cell lines Jurkat $(81 \mu \mathrm{M})$, HL60 $(>100 \mu \mathrm{M})$, Molt3 $(64 \mu \mathrm{M})$, NCEB-1 (>100 $\mu \mathrm{M})$ and K562 $(65 \mu \mathrm{M})$ suggest only moderate antiproliferative activity. Interestingly, the same compound demonstrated higher activity against epimastigotes of $T$. cruz $i$ than the aforementioned compound classes (see introduction) that have been studied in recent years. These initial promising results will direct us in investigating how substituents on both rings of the molecule contribute to the overall activity against the parasite.

In conclusion, diaryldiazepine $\mathbf{4 b}$ is the most active against epimastigotes of T. cruzi and is 40 times more potent than the current medicine, benznidazole that is used to treat Chagas disease in Brazil. Studies are ongoing to investigate the possible biological mechanism of action.

\section{Experimental Section}

All commercial reagents were used as received. TLC analyses were performed using silica gel plates, using ultraviolet light $(254 \mathrm{~nm})$ or vanillin solution for visualization. Melting points are uncorrected. IR spectra were recorded using samples that were prepared between $\mathrm{NaCl}$ plates, or pressed in to $\mathrm{KBr}$ discs. For NMR data, the chemical shifts are reported in $\delta(\mathrm{ppm})$ referenced to residual protons and ${ }^{13} \mathrm{C}$ signals in deuterated chloroform or deuterated DMSO. The coupling constants $(J)$ are expressed in Hertz $(\mathrm{Hz})$. Mass spectra were recorded on a Shimadzu LCMS-IT-TOF mass spectrometer. Flavones 3a-f were prepared according to literature methods [18].

\subsection{Chemistry}

General method for the preparation of 5,7-diaryl-2,3-dihydro-1,4-diazepine derivatives is based on the protocol described by Ramajayam and co-workers [6] and involves refluxing a mixture of flavone $(5-15 \mathrm{mmol})$ in ethylenediamine $(20 \mathrm{~mL})$ for $2 \mathrm{~h}$. The cooled mixture was poured into ice water and the yellow precipitate was filtered and finally recrystallized from methanol to give analytically pure samples. 
5-(2-Hydroxyphenyl)-7-phenyl-2,3-dihydro-1H-1,4-diazepine. Compound 4a was obtained as a yellow solid in 57\% yield. MP. 209-211 ${ }^{\circ} \mathrm{C}$ (Lit MP. 208-210 ${ }^{\circ} \mathrm{C}$ [6]); (300 MHz, DMSO-d6) $\delta: 8.0$ (1H, brs), $7.38-7.58$ (7H, m), $7.0(1 \mathrm{H}, \mathrm{t}, J 8.5), 6.74(1 \mathrm{H}, \mathrm{d}, J 8.0), 6.45(1 \mathrm{H}, \mathrm{t}, J 8.0), 5.6(1 \mathrm{H}, \mathrm{s}), 3.8(2 \mathrm{H}, \mathrm{bs})$, $3.6(2 \mathrm{H}, \mathrm{bs}) ; \delta_{\mathrm{c}}(75 \mathrm{MHz}, \mathrm{DMSO}-\mathrm{d} 6): 170.2,167.2,158.9,140.4,136.2,132.5,129.6,127.19,127.8$, $121.2,117.1,114.1,86.1,50.4,49.3$.

5-(2-Hydroxyphenyl)-7-(4-chlorophenyl)-2,3-dihydro-1H-1,4-diazepine. Compound 4b was obtained as a yellow solid in almost quantitative yield. MP. $238-240{ }^{\circ} \mathrm{C}$ (Lit MP. $243-245^{\circ} \mathrm{C}$ [6]); $v_{\max }\left(\mathrm{cm}^{-1}\right)$ : 1570, 1529, 1490, 1439, 1318, 1289, 1260, 1143, 837, 751; $\delta_{\mathrm{H}}\left(300 \mathrm{MHz}, \mathrm{DMSO}-\mathrm{d}_{6}\right):$ 7.66-7.45 (5H, m), $7.08(1 \mathrm{H}, \mathrm{t}, J 7.8), 6.56(1 \mathrm{H}, \mathrm{d}, J 8.2), 6.38(1 \mathrm{H}, \mathrm{t}, J 7.0), 5.61(1 \mathrm{H}, \mathrm{s}), 3.65$ and $3.95(4 \mathrm{H}, \mathrm{bs}) ; \delta_{\mathrm{c}}(75 \mathrm{MHz}$, DMSO-d6): 170.8, 168.2, 157.8, 137.7, 135.2, 132.7, 129.8, 129.3, 129.0, 128.7, 128.0, 121.7, 116.9, 113.2, 86.6, 49.9, 49.0, 31.1.

5-(2-Hydroxyphenyl)-7-(4-methylphenyl)-2,3-dihydro-1H-1,4-diazepine. Compound 4c was obtained as a yellow solid in $47 \%$ yield. MP. $233-235{ }^{\circ} \mathrm{C}$ (Lit.MP. $235-237{ }^{\circ} \mathrm{C}$ [6]); $v_{\max }\left(\mathrm{cm}^{-1}\right)$ : 3221,2922 , 1604: $\delta_{\mathrm{H}}\left(300 \mathrm{MHz}, \mathrm{DMSO}-\mathrm{d}_{6}\right): 8.14(1 \mathrm{H}, \mathrm{s}), 7.59-7.51(3 \mathrm{H}, \mathrm{m}), 7.28(2 \mathrm{H}, \mathrm{d}, J 8.0), 7.07$ (1H, t, J 7.0), $6.54\left(1 \mathrm{H}, \mathrm{d}, J\right.$ 8.5), $6.37(1 \mathrm{H}, \mathrm{t}, J 8.0), 5.62(1 \mathrm{H}, \mathrm{s}), 3.81(2 \mathrm{H}, \mathrm{s}), 3.56(2 \mathrm{H}, \mathrm{s}), 2.35(3 \mathrm{H}, \mathrm{s}) ; \delta_{\mathrm{c}}(75 \mathrm{MHz}$, DMSO-d $)$ : 170.8, 168.2, 158.9, 140.4, 136.2, 132.5, 129.6, 127.9, 127.8, 121.6, 117.1, 113.1, 86.1, $50.0,49.0,21.3$.

5-(2-Hydroxyphenyl)-7-(3,4,5-trimethoxyphenyl)-2,3-dihydro-1H-1,4-diazepine. Compound 4d was obtained as a yellow solid in $43 \%$ yield and is a novel compound. MP. $229-230{ }^{\circ} \mathrm{C} ; v_{\max }\left(\mathrm{cm}^{-1}\right): 1582$, 1531, 1499, 1309, 1244, 1124, 1009, 756; $\delta_{\mathrm{H}}\left(300 \mathrm{MHz}, \mathrm{DMSO}-\mathrm{d}_{6}\right): 8.12$ (1H, brs), 7.64 (1H, d, J 8.5), $7.08(1 \mathrm{H}, \mathrm{t}, J 7.8), 6.56(1 \mathrm{H}, \mathrm{d}, J$ 8.3), $6.42(1 \mathrm{H}, \mathrm{t}, J 7.0), 5.67(1 \mathrm{H}, \mathrm{s}), 3.84(6 \mathrm{H}, \mathrm{s}), 3.69(3 \mathrm{H}, \mathrm{s}), 3.54$ (4H, bs); $\delta_{\mathrm{C}}\left(75 \mathrm{MHz}, \mathrm{DMSO}-\mathrm{d}_{6}\right): 172.5,170.5,158.7,153.1,134.5,132.4,128.2,121.4,117.3,113.2$, 105.5, 86.2, 60.5, 56.5, 50.2, 49.1; MS $m / z$ (EI): calcd. for $\mathrm{C}_{20} \mathrm{H}_{22} \mathrm{~N}_{2} \mathrm{O}_{4} 354.1580$, found 354.1571.

5-(2-Hydroxyphenyl)-7-(4-fluorophenyl)-2,3-dihydro-1H-1,4-diazepine. Compound 4e was obtained as a yellow solid in $49 \%$. MP. $235-236{ }^{\circ} \mathrm{C}$ (MP. $234-236{ }^{\circ} \mathrm{C}$ Lit. [6]); $v_{\max }\left(\mathrm{cm}^{-1}\right)$ : 1603, 1531, 1499, 1440, 1318, 1259, 1224, 1168, 1144, 845, 783, 751; $\delta_{\mathrm{H}}$ (300 MHz, DMSO-d6): 7.68 (2H, t, J 8.7), 7.59 $(1 \mathrm{H}, \mathrm{d}, J$ 8.4), 7.3 (2H, t, $J$ 8.7), $7.08(1 \mathrm{H}, \mathrm{t}, J 6.9), 6.55(1 \mathrm{H}, \mathrm{d}, J 9.3), 6.38(1 \mathrm{H}, \mathrm{t}, J 8.1), 3.65$ and $3.95(4 \mathrm{H}, \mathrm{bs}) ; \delta_{\mathrm{C}}\left(75 \mathrm{MHz}, \mathrm{DMSO}-\mathrm{d}_{6}\right): 171.3,168.4,165.5$ and 162.2 (d, $\left.J_{\mathrm{CF}} 247.5\right), 158.4,135.639$ and 135.601 (d, $\left.J_{\mathrm{CF}} 2.9\right), 132.9,130.6,130.5,130.5,128.3,122.0,117.1,116.3$ and $116.0\left(\mathrm{~d}, J_{\mathrm{CF}} 59.7\right)$, $113.3,86.6,50.0,49.2$.

5-(2-Hydroxyphenyl)-7-(2-furyl)-2,3-dihydro-1H-1,4-diazepine. Compound $\mathbf{4 f}$ was obtained as a yellow solid in $77 \%$ yield. M.P. $175-178{ }^{\circ} \mathrm{C}$ (Lit MP. $\left.168-170{ }^{\circ} \mathrm{C}[6]\right) ; v_{\max }\left(\mathrm{cm}^{-1}\right): 1602,1537,1511,1329$, 1301, 1253, 1149, 1023. $\delta_{\mathrm{H}}\left(300 \mathrm{MHz}, \mathrm{DMSO}-\mathrm{d}_{6}\right): 7.87(1 \mathrm{H}, \mathrm{s}), 7.66(1 \mathrm{H}, \mathrm{d}, J$ 8.4), 7.21 (1H, d, J 3.3), $7.1(1 \mathrm{H}, \mathrm{t}, J 8.1), 6.68-6.66(1 \mathrm{H}, \mathrm{m}), 6.56(1 \mathrm{H}, \mathrm{d}, J 9.3), 6.44(1 \mathrm{H}, \mathrm{t}, J 8.1), 6.03(1 \mathrm{H}, \mathrm{s}), 3.65$ and 3.95 (4H, bs); $\delta_{\mathrm{C}}\left(75 \mathrm{MHz}, \mathrm{DMSO}-\mathrm{d}_{6}\right): 171.1,168.5,150.1,147.1,145.7,132.9,128.1,121.9,117.2,113.5$, $113.2,111.7,83.0,50.0,48.8$. 


\subsection{Pharmacology}

The $\mathrm{IC}_{50}$ values of the drug concentration $(\mu \mathrm{M})$ necessary to kill $50 \%$ of the parasites, was obtained by linear regression analysis.

\subsection{Anti-Trypanosoma cruzi Activity}

In this study, epimastigotes of the $\mathrm{Y}$ strain from T. cruzi were used. Epimastigotes obtained in exponential growth phase were washed with LIT medium 2 times in sterile PBS at pH 7.2 (1500 g) for $10 \mathrm{~min}$ at $4{ }^{\circ} \mathrm{C}$. The number of parasites was determined in a Neubauer chamber. Next, the parasites were suspended in LIT medium, which was further supplemented with 10\% FBS (Fetal Bovine Serum inactivated at $56^{\circ} \mathrm{C}$ ), and the concentration of epimastigotes adjusted to $5 \times 10^{6}$ epimastigotes $/ \mathrm{mL}$.

With the goal of screening samples with possible biological activity against $T$. cruzi, compounds were incubated in 48 well Nunc plates containing $800 \mu \mathrm{L}$ of the suspension of parasites and $200 \mu \mathrm{L}$ of the test compounds at different concentrations $(40,20,10$ and $1.6 \mu \mathrm{g} / \mathrm{mL})$ diluted in sterile DMSO for $72 \mathrm{~h}$ in duplicate. As a negative control, the parasites were incubated in the absence of test compound and in the presence of $1 \%$ DMSO. Benznidazole $(10 \mu \mathrm{g} / \mathrm{mL})$ was used as positive control in tests against $T$. cruzi. The activity was determined by counting in a Neubauer chamber and subsequent statistical evaluation. The results are expressed as $\mathrm{IC}_{50}$. The tests were repeated 2 times with the objective of evaluating the maintenance of the activity of the compounds and reproducibility of results.

\section{Acknowledgments}

This work was supported by the Brazilian funding agency Fundação de Amparo à Pesquisa do Estado de Minas Gerais (FAPEMIG) under research grant project code APQ-00307-12, APQ-00356-13 and the Conselho Nacional de Desenvolvimento Científico e Tecnológico (CNPq) under research grant project code 473461/2013-7. Authors gratefully acknowledge the generous financial support from the Universidade Federal de Ouro Preto, FAPEMIG and the Conselho Nacional de Desenvolvimento Científico e Tecnológico (CNPq).

\section{Author Contributions}

JCLM carried out the synthesis of the diaryldiazepines; LBAV, PMAV, KSF and CMC evaluated the biological activity against T. cruzi; JGT, PMAV and CMC wrote the paper. All authors read and approved the final manuscript.

\section{Conflicts of Interest}

The authors declare no conflict of interest.

\section{References}

1. Nakanishi, M.; Tahara, T.; Araki, K.; Shiroki, M.; Tsumagari, T.; Takigawa, T. Psychotropic drugs. 18. Synthesis and structure-activity relations of 5-phenyl-1,3-dihydro-2H-thieno[2,3-e][1,4]diazepin2-ones. J. Med. Chem. 1973, 16, 214-219. 
2. Eweas, A.F.; Allam, G.; Abuelsaad, A.S.; ALGhamdi, A.H.; Maghrabi, I.A. Design, synthesis, anti-schistosomal activity and molecular docking of novel 8-hydroxyquinoline-5-sufonyl 1, 4-diazepine derivatives. Bioorg. Chem. 2013, 46, 17-25.

3. Moure, A.; Orzaez, M.; Sancho, M.; Messeguer, A. Synthesis of enantiomerically pure perhydro-1,4-diazepine-2,5-dione and 1,4-piperazine-2,5-dione derivatives exhibiting potent activity as apoptosis inhibitors. Bioorg. Med. Chem. Lett. 2012, 22, 7097-7099.

4. Gaggini, F.; Laleu, B.; Orchard, M.; Fioraso-Cartier, L.; Cagnon, L.; Houngninou-Molango, S.; Gradia, A.; Duboux, G.; Merlot, C.; Heitz, F.; et al. Design, synthesis and biological activity of original pyrazolo-pyrido-diazepine, -pyrazine and -oxazine dione derivatives as novel dual Nox4/Nox1 inhibitors. Bioorg. Med. Chem. 2011, 19, 6989-6999.

5. El-Subbagh, H.I.; Hassan, G.S.; El-Azab, A.S.; Abdel-Aziz, A.A.-M.; Kadi, A.A.; Al-Obaid, A.M.; Al-Shabanah, O.A.; Sayed-Ahmed, M.M. Synthesis and anticonvulsant activity of some new thiazolo[3,2- $a][1,3]$ diazepine, benzo[ $d]$ thiazolo[5,2-a][12,6]diazepine and benzo[ $d]$ oxazolo[5,2-a] [12,6]diazepine analogues. Eur. J. Med. Chem. 2011, 46, 5567-5572.

6. Ramajayam, R.; Giridhar, R.; Yadav, M.R.; Djaballah, H.; Shum, D.; Radu, C. Synthesis and antiproliferative activity of some diaryldiazepines and diarylpyrimidines. J. Enzym. Inhib. Med. Chem. 2007, 22, 716-721.

7. Chagas, C. Nova tripanossomíase humana, Estudos sobre a morfologia e o ciclo evolutivo do Schizotrypanum cruzi n. gen., n. sp., ajente etiolójico de nova entidade mórbida do homem. Mem. Inst. Oswaldo Cruz. 1909, 1, 159-218.

8. World Health Organization (2010). First WHO Report on Neglected Tropical Diseases: Working to Overcome the Global Impact of Neglected Tropical Diseases. Available online: http://whqlibdoc.who.int/publications/2010/9789241564090_eng.pdf (accessed on 14 October 2014).

9. Hotez, P.J.; Dumonteil, E.; Woc-Colburn, L.; Serpa, J.A.; Bezek, S.; Edwards, M.S.; Hallmark, C.J.; Musselwhite, L.W.; Flink, B.J.; Bottazzi, M.E. Chagas Disease: "The New HIV/AIDS of the Americas". PLoS Negl. Trop. Dis. 2012, 6, e1498.

10. Rodriques Coura, J.; de Castro, S.L. A critical review on Chagas disease chemotherapy. Mem. Inst. Oswaldo Cruz 2002, 97, 3-24.

11. Wilkinson, S.R.; Kelly, J.M. Trypanocidal drugs: Mechanisms, resistance and new targets. Expert Rev. Mol. Med. 2009, 11, doi:10.1017/S1462399409001252.

12. Moreira, D.R.M.; Lima Leite, A.C.; Cardoso, M.V.O.; Srivastava, R.M.; Hernandes, M.Z.; Rabello, M.M.; da Cruz, L.F.; Ferreira, R.S.; de Simone, C.A.; Meira, C.S.; et al. Structural Design, Synthesis and Structure-Activity Relationships of Thiazolidinones with Enhanced Anti-Trypanosoma cruzi Activity. ChemMedChem 2014, 9, 177-188.

13. Franklim, T.N.; Freire-de-Lima, L.; de Nazareth Sá Diniz, J.; Previato, J.O.; Castro, R.N.; Mendonça-Previato, L.; de Lima, M.E.F. Design, Synthesis and Trypanocidal Evaluation of Novel 1,2,4-Triazoles-3-thiones Derived from Natural Piperine. Molecules 2013, 18, 6366-6382.

14. Ricardo, A.T.; Cristian, O.S.; Karina, V.; Christian, E.-B.; Jorge, S.-D.; Javier, V.; Estefanía, B.; Hugo, C.; Mercedes, G.; Margot, P. Synthesis and biological characterization of new aryloxyindole-4,9-diones as potent trypanosomicidal agents. Bioorg. Med. Chem. Lett. 2014, 24, 3919-3922. 
15. Caputto, M.E.; Ciccarelli, A.; Frank, F.; Moglionia, A.G.; Moltrasio, G.Y. Synthesis and biological evaluation of some novel 1-indanone thiazolylhydrazone derivatives as anti-Trypanosoma cruzi agents. Eur. J. Med. Chem. 2012, 55, 155-163.

16. Dos Santos, J.M.; Moreira, D.R.M.; de Simone, C.A.; Ferreira, R.S.; McKerrow, J.H.; Meira, C.S.; Guimaraes, E.T.; Soares, M.B.P. Optimization of anti-Trypanosoma cruzi oxadiazoles leads to identification of compounds with efficacy in infected mice, Bioorg. Med. Chem. 2012, 20, 6423-6433.

17. Sandes, J.M.; Borges, A.R.; Junior, C.G.; Silva, F.P.; Carvalho, G.A. 3-Hydroxy-2-methylene-3(4-nitrophenylpropanenitrile): A new highly active compound against epimastigote and trypomastigote form of Trypanosoma cruzi. Bioorg. Chem. 2010, 38, 190-195.

18. Wheeler, T.S. Flavone. Org. Synth. 1952, 32, 72-74.

Sample Availability: Samples of the compounds $\mathbf{4 a - f}$ are available from the authors.

(C) 2014 by the authors; licensee MDPI, Basel, Switzerland. This article is an open access article distributed under the terms and conditions of the Creative Commons Attribution license (http://creativecommons.org/licenses/by/4.0/). 